\title{
COMPORTAMENTO AGRONÔMICO DE CULTIVARES E HÍBRIDOS DE REPOLHO NA REGIÃO NORDESTE DO RIO GRANDE DO SUL
}

\author{
AGRONOMIC BEHAVIOR OF CABBAGE CULTIVARS AND HYBRIDS \\ IN THE NORTHEAST REGION OF RIO GRANDE DO SUL, BRAZIL
}

\author{
Fernando Fracaro ${ }^{1}$ Marcelo Sartori $^{2}$ Ernesto Bizzani ${ }^{3}$ \\ Etmar Grelman ${ }^{4}$ Sergio Echeverrigaray ${ }^{5}$
}

\section{RESUMO}

\begin{abstract}
O repolho (Brassica oleracea var. capitata) é uma das plantas hortícolas mais importantes na região nordeste do Rio Grande do Sul. Assim sendo, o objetivo do presente trabalho foi identificar os melhores cultivares e híbridos de repolho para esta região. Quinze materiais comerciais de repolho, de distintos distribuidores e origens, foram avaliados quanto ao seu comportamento agronômico em Veranópolis, $R S$, de julho a novembro de 1997, adotando a tecnologia usualmente recomendada para esta região. As maiores produtividades foram obtidas com os híbridos Shinsei (54,8t/ha), Japonês $(53,6 t / h a)$, Astrus $(48,6 t / h a)$ e Kenzan (44,8t/ha), e o cultivar Brunswick (43,5t/ha). Entretanto, considerando a preferência do mercado por repolhos de 1 a 1,5kg, os melhores materiais foram Saikô, Coração de Boi, Fuyutoyo, Chato de Quintal and Midori, com produtividades da ordem de 32 a $40 t / h a$.
\end{abstract}

Palavras-chave: repolho, competição de cultivares, produção.

\section{SUMMARY}

Cabbage (Brassica oleracea var. capitata) is one of the most important horticultural plants in the northeast region of Rio Grande do Sul State. The objective of the present study was to identify the best cultivar and hybrid of cabbage for this region. Fifteen commercial materials of cabbage, from different distributors and origins, were evaluated for their agronomic behavior in Veranópolis, Rio Grande do Sul, from July to November, 1997, adopting the technology usually recommended for this region. The best productivities were obtained with the hybrids Shinsei (54.8t/ha), Japonês (53.6t/ha), Astrus (48.6t/ha) and Kenzan (44.8t/ha), and the cultivar Brunswick (43.5t/ha). However, considering the preference of the market for cabbages of 1 to $1.5 \mathrm{~kg}$, the best materials were Saikô, Coração de Boi, Fuyutoyo, Chato de Quintal and Midori, with productivities of the order of 32 to $40 \mathrm{t} / \mathrm{ha}$.

Key words: cabbage, cultivars competition, production.

\section{INTRODUÇÃO}

O repolho (Brassica oleracea var. capitata L.) é, considerando os volumes plantados e comercializados, a mais importante das variedades de Brassica oleracea e uma das plantas olerícolas de maior relevância. Segundo dados do SINAC e da CEAGESP, no Brasil, são comercializadas anualmente cerca de 500 mil toneladas de repolho, tendo como principais centros produtores, os Estados de São Paulo, Rio de Janeiro e Minas Gerais (COSTA, 1986).

No Rio Grande do Sul, a produção hortícola encontra-se espalhada por várias regiões, principalmente o litoral e a serra. Entretanto, a região serrana do Nordeste do Estado se constitui no maior pólo hortifrutigrangeiro, abastecendo grande parte da demanda do Estado.

Os trabalhos de melhoramento de brássicas no Brasil tiveram início na década de 40, com o surgimento dos primeiros cultivares nacionais. A partir da década de 60, ocorreu a introdução de hí-

\footnotetext{
${ }^{1}$ Aluno do Curso de Horticultura, Bolsista do PIBIC/CNPq, Campus de Veranópolis, Universidade Caxias do Sul (UCS).

${ }^{2}$ Aluno do Curso de Horticultura, Campus de Veranópolis, UCS.

${ }^{3}$ Químico, Centro de Pesquisa da Pequena Propriedade de Veranópolis, FEPAGRO/SCT.

${ }^{4}$ Engenheiro Agrônomo, Centro de Pesquisa da Pequena Propriedade de Veranópolis, FEPAGRO/SCT.

${ }^{5}$ Biólogo, Doutor, Instituto de Biotecnologia, Departamento de Ciências Biológicas, UCS, CP 1532, 95001-970, Caxias do Sul, RS. Autor para correspondência. 
bridos de várias procedências, especialmente japoneses, que dadas as suas boas características agronômicas ocuparam grande parte do mercado, principalmente na Região Sul (PINHO et al., 1982). As condições climáticas peculiares do Brasil, tais como alta umidade, temperaturas médias elevadas e a ocorrência de alternâncias de temperaturas, tornaram necessária a continuidade dos trabalhos de melhoramento, entre os quais se destacam aqueles direcionados à resistência a doenças, como a podridão negra (Xanthomonas campestris pv. campestris) em cultivares e híbridos de verão (SILVA JÚNIOR, 1986; HENZ et al., 1987). No mercado atual, existem vários cultivares e híbridos de diferentes procedências, recomendados para distintas regiões e épocas de plantio. Entretanto, a falta de dados a respeito do comportamento agronômico destes materiais em regiões específicas e nas condições de cultivo adotadas nas mesmas, torna difícil a escolha por parte do agricultor.

Apesar da importância da cultura do repolho no Nordeste do RS, poucas pesquisas têm sido realizadas no sentido de avaliar o comportamento agronômico de cultivares e híbridos, quanto à produtividade e outras características relevantes dos materiais disponíveis no mercado, o que constitui o objetivo deste trabalho.

\section{MATERIAL E MÉTODOS}

O experimento foi realizado na Estação Experimental da FEPAGRO em Veranópolis, RS. No ensaio, foram avaliados os cultivares Chato de Quintal, Coração de Boi, Louco de Verão e Roxo, e os híbridos, 60 Dias e Híbrido Japonês, distribuídos pela ISLA S.A.; o cultivar Brunswick e o híbrido 4 Estações, distribuídos por FELTRIN; o híbrido Fuyutoyo, comercializado por AGROCERES; o híbrido Astrus, da ASGROW; os híbridos Kenzan e Midori, distribuídos por AGROFLORA; o híbrido Shinsei, comercializado pela TOHOKU; e os híbridos Midori e Scarlet O'Hara, distribuídos pela TOKITA. Os híbridos, com exceção de Astrus e 4 Estações, são de origem japonesa. O cultivar Roxo, conhecido como Mammoth Red Rock, e o híbrido Scarlet O'Hara, representam os repolhos roxos mais importantes.

Utilizou-se o delineamento experimental em blocos ao acaso com 15 tratamentos e três repetições. Cada parcela experimental foi constituída por 30 plantas em espaçamento de $0,8 \mathrm{~m} \times 0,6 \mathrm{~m}$, sendo somente consideradas as dez plantas centrais. A semeadura foi realizada em 30 de Junho de 1997 em bandejas, mantidas em estufa com irrigação por aspersão. $\mathrm{O}$ transplantio foi realizado em 27 de julho de 1997 em canteiros, nos quais foram incorporados $11,7 \mathrm{~T} / \mathrm{ha}$ de calcário (Filler), 140kg/ha de nitrogênio, $200 \mathrm{~kg} / \mathrm{ha}$ de fósforo e $50 \mathrm{~kg} / \mathrm{ha}$ de potássio. Nitrogênio foi aplicado em cobertura aos 20 e 60 dias após transplantio, na dosagem de $83 \mathrm{~kg} / \mathrm{ha}$. O controle de ervas daninhas foi feito através de capinas, sendo realizada uma única aplicação de inseticida aos 60 dias após transplantio (Decis $25 \mathrm{CE}$.) para controle de pulgões.

Por ocasião da colheita, realizada entre 27 de novembro e 7 de dezembro de 1997, foram avaliados os seguintes parâmetros: massa fresca total (cabeça e folhas), massa comercial (cabeças livres de rachaduras e/ou danos causados por pragas e doenças), diâmetro médio longitudinal e transversal, diâmetro basal e altura do caule, e ocorrência de doenças e pragas. Determinado-se o índice de formato (altura vs. largura), volume da cabeça, índice de compacidade, pela razão entre massa e volume, e índice de altura do caule, pela razão entre a altura do caule e da cabeça.

Os resultados experimentais foram analisados através de testes de ANOVA, com comparação de médias através do teste de Tukey, com o auxílio do programa SPSS-Windows 6.0 (Student Version).

\section{RESULTADOS E DISCUSSÃO}

Os resultados obtidos, apresentados na tabela 1, demonstraram que os híbridos Shinsei, Híbrido Japonês, Astrus e Kenzan, foram os mais produtivos. Entre os cultivares, sobressaiu o cultivar Brunswick. Em termos de produtividade, observaram-se valores superiores à média mundial (20,2t/ha) e à média nacional (30,0t/ha), (COBBE, 1983). Cabe ressaltar, que o cultivar e o híbrido mais utilizados na região, Coração de Boi e Fuyutoyo, apresentaram produtividades intermediárias, sendo as mesmas significativamente inferiores às dos híbridos Shinsei e Japonês. O cultivar Louco de Verão, utilizado neste experimento para verificar o comportamento no inverno de materiais de verão, apresentou altos índices de florescimento (90\%), sendo portanto impossível avaliar a sua produtividade. Dentro dos repolhos roxos avaliados, o cultivar Roxo apresentou melhor produção do que o híbrido Scarlet O'Haara, e ambos apresentaram produções inferiores à média dos repolhos brancos.

Quanto à massa média da cabeça, os maiores repolhos foram o Shinsei, o híbrido Japonês e o Astrus, 2,19, 2,14 e 1,94kg, respectivamente. Entretanto, os valores obtidos são consideravelmente elevados, levando em consideração a tendência de mercado de consumo de repolhos de cabeça mediana 
Tabela 1 - Comparação do comportamento agronômico de cultivares e híbridos de repolho em Veranópolis no período de julho a dezembro, 1997.

\begin{tabular}{|c|c|c|c|c|c|c|c|}
\hline $\begin{array}{l}\text { Cultivares e } \\
\text { Híbridos }\end{array}$ & $\begin{array}{l}\text { Produção Comercial } \\
\text { (t/ha) }\end{array}$ & $\begin{array}{l}\text { Massa Média da } \\
\text { Cabeça (Kg) }\end{array}$ & $\begin{array}{l}\text { Volume da Cabeça } \\
\qquad\left(\mathrm{cm}^{3}\right)\end{array}$ & $\begin{array}{l}\text { Altura da Cabeça } \\
\qquad(\mathrm{cm})\end{array}$ & $\begin{array}{l}\text { Largura da Cabeça } \\
(\mathrm{cm})\end{array}$ & $\begin{array}{l}\text { Indice Altura } \\
\text { do Caule }\end{array}$ & $\begin{array}{l}\text { Indice } \\
\text { Compac. }\end{array}$ \\
\hline Shinsei & $54,82 \pm 3,29 \mathrm{a}$ & $2,19 \pm 0,13 \mathrm{a}$ & $3138,1 \pm 158,9 \mathrm{ab}$ & $16,13 \pm 0,41 \mathrm{bc}$ & $19,05 \pm 0,29 b$ & $58,09 \mathrm{ab}$ & $0,62 \mathrm{bcd}$ \\
\hline Hib. Japonês & $53,57 \pm 3,42 \mathrm{ab}$ & $2,14 \pm 0,14 \mathrm{a}$ & $3274,6 \pm 227,8 \mathrm{a}$ & $14,57 \pm 0,36 \mathrm{de}$ & $20,27 \pm 0,51 \mathrm{a}$ & $68,65 \mathrm{a}$ & $0,67 \mathrm{bcd}$ \\
\hline Astrus & $48,56 \pm 3,26 a b c$ & $1,94 \pm 0,13 a b$ & $2761,5 \pm 184,7 \mathrm{abc}$ & $15,08 \pm 0,46 \mathrm{bcd}$ & $18,32 \pm 0,37 \mathrm{bc}$ & $52,53 \mathrm{~b}$ & $0,71 \mathrm{bcd}$ \\
\hline Kenzan & $44,78 \pm 2,02 \mathrm{abcd}$ & $1,79 \pm 0,08 b c$ & $2542,3 \pm 131,2 \mathrm{bcd}$ & $14,20 \pm 0,29$ de & $18,30 \pm 0,30 \mathrm{bc}$ & $65,26 a$ & $0,73 \mathrm{abc}$ \\
\hline Brunswick & $43,46 \pm 2,31 \mathrm{bcd}$ & $1,74 \pm 0,09 \mathrm{bcd}$ & $2403,7 \pm 126,8$ cde & $15,08 \pm 0,50 \mathrm{bcd}$ & $17,33 \pm 0,30 \mathrm{~cd}$ & $48,42 \mathrm{~b}$ & $0,72 \mathrm{ab}$ \\
\hline Saikô & $39,48 \pm 2,31$ cde & $1,57 \pm 0,09 \mathrm{cde}$ & $2183,6 \pm 94,0$ cdef & $14,90 \pm 0,34 \mathrm{~cd}$ & $16,60 \pm 0,21 \mathrm{de}$ & $52,25 \mathrm{~b}$ & $0,73 \mathrm{bcd}$ \\
\hline Cor. de Boi & $38,56 \pm 2,07$ cde & $1,54 \pm 0,09 \mathrm{cde}$ & $2730,5 \pm 158,2 \mathrm{bc}$ & $20,92 \pm 0,48 \mathrm{a}$ & $15,58 \pm 0,38$ e & $50,21 \mathrm{~b}$ & $0,59 \mathrm{~d}$ \\
\hline Fuyutoyo & $36,96 \pm 2,07 \mathrm{de}$ & $1,47 \pm 0,08$ def & $1945,5 \pm 95,6 \operatorname{def}$ & $13,51 \pm 0,32$ ef & $16,37 \pm 0,30$ de & $50,05 \mathrm{~b}$ & $0,76 \mathrm{ab}$ \\
\hline Ch. Quintal & $36,38 \pm 1,94$ de & $1,45 \pm 0,08$ ef & $2175,7 \pm 125,1$ cdef & $16,28 \pm 0,42 b$ & $15,73 \pm 0,36 \quad \mathrm{e}$ & $49,26 \mathrm{~b}$ & $0,71 \mathrm{bcd}$ \\
\hline Midori & $31,67 \pm 1,77$ ef & $1,27 \pm 0,07 \quad$ fg & $1739,4 \pm 113,3 \quad \mathrm{f}$ & $12,85 \pm 0,39 \quad f$ & $15,78 \pm 0,32$ e & $49,66 \mathrm{~b}$ & $0,75 \mathrm{ab}$ \\
\hline 60 Dias & $30,41 \pm 1,72$ ef & $1,21 \pm 0,07 \quad \mathrm{fg}$ & $1834,4 \pm 119,8$ ef & $14,30 \pm 0,32 \mathrm{de}$ & $15,37 \pm 0,40 \quad \mathrm{e}$ & $58,41 \mathrm{ab}$ & $0,68 \mathrm{bcd}$ \\
\hline 4 Estações & $28,92 \pm 2,08$ ef & $1,16 \pm 0,08$ & $1991,5 \pm 120,7$ def & $12,58 \pm 0,34 \quad f$ & $17,13 \pm 0,39 \mathrm{~cd}$ & $50,52 \mathrm{~b}$ & $0,59 \mathrm{~cd}$ \\
\hline Roxo & $21,94 \pm 1,15 \quad \mathrm{fg}$ & $0,88 \pm 0,04$ & $1033,1 \pm 59,4 \quad \mathrm{~g}$ & $12,90 \pm 0,20 \quad \mathrm{f}$ & $12,18 \pm 0,27 \quad f$ & $57,98 \mathrm{ab}$ & $0,73 \mathrm{abc}$ \\
\hline Scarlet & $12,84 \pm 0,92 \quad \mathrm{~g}$ & $0,51 \pm 0,04$ & $725,8 \pm 48,4$ & $12,33 \pm 0,26 \quad f$ & $10,40 \pm 0,26 \quad \mathrm{~g}$ & $52,75 \mathrm{~b}$ & 0,86 a \\
\hline Louco $^{*}$ & $3,17 \pm 1,81$ & & & & & & \\
\hline
\end{tabular}

* O cultivar Louco de Verão floresceu (90\%), impedindo a sua avaliação.

Médias seguidas por letras distintas diferem significativamente pelo teste de Tukey $(\mathrm{p}=0,01)$.

$(1,0$ a $1,5 \mathrm{~kg})$ (DICKSON \& WALLACE, 1986).

Neste sentido, os híbridos Fuyutoyo e Midori, e os cultivares Coração de Boi e Chato de Quintal, apresentaram valores ótimos dentro das condições experimentais adotadas. Os materiais com alta massa média de cabeça poderiam ser plantados em espaçamento menor, provocando a redução das mesmas, mas mantendo altas produtividades.

A maior parte dos materiais avaliados apresentaram cabeças achatadas, como indicam os índices de formato, ressaltando o híbrido Japonês, 4 Estações e Kenzan com índices de 0,72 a 0,78. Os repolhos redondos foram representados pelos materiais, 60 Dias, Chato Quintal e Roxo. Apenas dois materiais, Scarlet O'Haara e Coração de Boi apresentaram cabeça alongada, com índices de 1,20 e 1,36, respectivamente. Estes resultados concordam com aqueles obtibos por GIORDANO et al. (1985), COSTA (1986) e MUNIZ (1988).

O grau de compacidade permitiu separar os materiais em compactos, médios e fofos. Entre os compactosressaltaram-se o cultivar Coração de Boi $(0,59)$, e os híbridos, 4 Estações $(0,60)$, Japonês $(0,67)$, Fuyutoyo $(0,68)$ e Shinsei $(0,69)$. O material de menor compacidade foi o híbrido Roxo $(0,86)$. Os demais cultivares apresentaram valores intermediários, considerados como de compacidade média. Quanto ao estado fitossanitário dos materias testados, foi observada baixa incidência de bacteriose e algum dano por pulgão. Os materias que apresentaram maior incidência de bacterioses foram 4 Estações, com 26,6\% das cabeças afetadas, e Saikô, com $13,3 \%$. As bacterioses, de um modo geral, segundo DICKSON \& WALLACE, 1986, não representam um sério problema nas produções de inver- no/primavera em clima temperado, exceto quando se trata de plantios em estufas ou outros ambientes de alta umidade. Entretanto, no Sul do Brasil, com a ocorrência de veranicos em julho e agosto, e temperaturas elevadas durante o mês de setembro, as bacterioses representam um risco considerável. Assim sendo, é preferível a utilização de materiais resistentes ou tolerantes a bacterioses, tais como a podridão negra, causada por Xanthomonas campestris pv. campestris, e a podridão mole, causado por Erwinia carotovora.

Segundo DICKSON e WALLACE (1986), um importante caráter em repolho é o tamanho do caule em comparação com a altura da cabeça, sendo preferíveis os materiais com menor caule. Os resultados observados possibilitam indicar dois materiais com caule longo: Híbrido Japonês e Kenzan. $\mathrm{O}$ restante dos materiais apresentaram índices inferiores a $60 \%$.

\section{CONCLUSÃO}

Os híbridos Saikô, Fuyutoyo, Midori e os cultivares Coração de Boi e Chato de Quintal apresentam boa produtividade, massa individual e sanidade na região de Veranópolis, no período de cultivo julho/dezembro. Apesar de não se destacarem como os materiais mais produtivos, estes apresentam cabeças com massa intermediária acompanhando a tendência do mercado consumidor. Os híbridos Shinsei, Híbrido Japonês, Astrus e Kenzan, e o cultivar Brunswick apresentam altas produtividades, boa sanidade, mas massa individual acima daquela ideal para o mercado. 


\section{REFERÊNCIAS BIBLIOGRÁFICAS}

COBBE, R.V. Reavaliando as hortaliças. Horticultura Brasileira, Brasília, v. 1, p. 10-17, 1983.

COSTA, N.D. Instruções para a cultura do repolho. Salvador: EPABA, 1986. 20 p.

DICKSON, M.H., WALLACE, D.H. Breeding vegatable crops. New York: AVI, 1986. Cap. 11: Cabbage Breeding: p. 395432 .

GIORDANO, L. de B., SILVA, N. da, CORDEIRO, C.M.T Experimentos comparativos entre híbridos e cultivares de repolho. Horticultura Brasileira, Brasília, v. 3, p. 29-31, 1985.
HENZ, P.G., REIFSCHEIDER, F.J.B., TAKATSU, A., $\boldsymbol{e} \boldsymbol{t}$ al . Identificação de fontes de resistência a Xanthomonas campestris PV campestris em Brássicas. Horticultura Brasileira, Brasília, v. 5, p. 18-20, 1987.

MUNIZ, J.O.L. Avaliação de cultivares e híbridos de repolho. Horticultura Brasileira, Brasília, v. 6, p. 14-15, 1988.

PINHO, A. de, MIRANDA, M.H., FARIAS, S.M.C., et al. Olerícolas. Sete anos de exportação, 1975-1981. Brasilia: Secretaria de Produção Agrícola, 1982. 20 p.

SILVA JUNIOR, A.A. Adubação mineral e orgânica em repolho.III. Qualidade comercial e ocorrência de Xanthomonas campestris. Horticultura Brasileira, Brasília, v. 4, p. 10-12, 1986.

Ciência Rural, v. 29, n. 3, 1999. 